University of New Hampshire

University of New Hampshire Scholars' Repository

$1-1-2012$

\title{
Is it time to forget science? Reflections on singular science and its history
}

Jan V. Golinski

University of New Hampshire, Durham, jan.golinski@unh.edu

Follow this and additional works at: https://scholars.unh.edu/history_facpub

\section{Recommended Citation}

Golinski, J.V. "Is it time to forget science? Reflections on singular science and its history," Osiris 27 (2012), 19-36.

This Article is brought to you for free and open access by the History at University of New Hampshire Scholars' Repository. It has been accepted for inclusion in History Scholarship by an authorized administrator of University of New Hampshire Scholars' Repository. For more information, please contact Scholarly.Communication@unh.edu. 


\title{
Is It Time to Forget Science? Reflections on Singular Science and Its History
}

\author{
by Jan Golinski*
}

\begin{abstract}
The name history of science reflects a set of assumptions about what science is. Among them is the claim that science is a singular thing, a potentially unified group of disciplines that share a common identity. Long promoted by scientists and philosophers on the basis of a supposedly universal scientific method, this claim now looks very embattled. I trace its development from the early nineteenth century and the growth of the positivist movement to its various manifestations in the twentieth century. Recently, some historians have called for the term science to be relinquished, and for adoption of a more relaxed pluralism. Yet the complex legacy of the notion of singular science cannot be so easily abandoned.
\end{abstract}

The history of science has a paradoxical relationship to the thing it studies. Although the name of the discipline embeds within it an assumption that a singular thing called science is the object of its attention, that object has become harder to pin down as historical and other studies have gone in search of it. Attempts to demarcate the boundaries of the activity we call science have been repeatedly frustrated; claims to have isolated its essence or to have traced its continuity through the centuries have been seriously challenged. The historicization of the category of science has ended up by fragmenting the entity in question. To speak of science as a single thing suggests a degree of unity, exclusivity, and long-term continuity that the historical record does not seem to manifest. Science as we know it today is harder to find the farther we recede from the present, as has often been observed by those who study the premodern or early modern periods. And when non-Western cultures are brought into focus, it is even more difficult to locate in its familiar form.

It seems, then, that the concept of science is ripe for critical examination. The term is central to the cultural capital of our field, in other words to the symbolic vocabulary by which it has secured its authority. It is part of a venerable tradition, and as such - as historians above all should understand-is not to be dispensed with by mere wishful thinking. On the other hand, there has been a growing realization that this word science is a peculiar and rather fraught inheritance. It embraces the specific ideas and practices of the scientific disciplines, along with a complex set of metascientific beliefs and values. What we take to be science includes, along with the

\footnotetext{
* Department of History, 20 Academic Way, University of New Hampshire, Durham, NH 03824; jan.golinski@unh.edu. I would like to thank the volume editors for their advice and support.
}

๑ 2012 by The History of Science Society. All rights reserved. 0369-7827/11/2012-0002\$10.00 
actual contents of scientific knowledge, a whole range of peripheral assertions about it. These include the claims that science has a privileged grasp of the truth, that it constitutes the only path to sound knowledge, that it enjoys a special freedom from social and political influences, that it is objective in its findings, and that it is universal in its application. Many of these claims have been subjected to fairly stringent criticism in recent years. It seems that such ideals as truth, value-neutrality, and objectivity are neither eternally unchanging nor universally accepted. Rather, they are historical constructs, interpreted in a range of different ways, and coming into prominence at particular times for particular reasons. Several important works of historical scholarship have mapped this terrain, and I do not need to reiterate their conclusions here. ${ }^{1}$

Instead, I want to see what can be brought into focus by pursuing a different but related metascientific theme: the notion that science is a singular entity, that all scientific beliefs and practices are components of one thing. This notion of "singular science" (as I shall call it) may be broken down into several component parts. It may rely on the assertion that all scientific disciplines adhere to one kind of method, for example, or at least that they draw upon a common set of approaches. It may invoke a kind of hierarchy of the sciences, insofar as they are thought to have advanced to different degrees in pursuit of their common goals. Singular science may involve an aspiration to unify all of the scientific disciplines at some point in the future. And it may also involve an insistence that science-as practiced in European civilization in the modern era-is a uniquely effective means of understanding and controlling the natural world.

I do not intend to disentangle all of the ancillary assumptions connected with the idea of singular science, as one might for the purposes of philosophical analysis. My aim is rather to explore the history of their entanglement. ${ }^{2}$ In doing this, I will show that the notion of singular science was advanced in response to the rise of a large number of new disciplines in the early nineteenth century. ${ }^{3}$ The fragmentation of the field of scientific inquiry called forth a vision of its potential unification. This ideal was particularly characteristic of the positivist philosophy, with its model of a scale of perfection on which all the scientific disciplines could be arranged. The positivist assertion that the disciplines had a common goal, which they would all eventually attain, allowed science to establish its credentials vis-à-vis other cultural domains in the period, such as religion and technology. Positivism also projected its vision of singular science globally, insisting that it was the only knowledge of nature that offered a path to material and social progress. Singular science was asserted as a component of European cultural hegemony in the nineteenth and early twentieth centuries.

\footnotetext{
${ }^{1}$ On the historical formation of notions of truth, value-neutrality, and objectivity, see Steven Shapin, A Social History of Truth: Civility and Science in Seventeenth-Century England (Chicago, 1994); Robert N. Proctor, Value-Free Science? Purity and Power in Modern Knowledge (Cambridge, Mass., 1991); Lorraine Daston and Peter Galison, Objectivity (New York, 2007).

2 This inquiry draws upon the work of several other historians, including Peter Galison and David J. Stump, eds., The Disunity of Science: Boundaries, Contexts, and Power (Stanford, Calif., 1996); Thomas F. Gieryn, Cultural Boundaries of Science: Credibility on the Line (Chicago, 1999); and Peter Dear, The Intelligibility of Nature: How Science Makes Sense of the World (Chicago, 2006).

${ }^{3}$ On this, see Richard G. Olson, Science and Scientism in Nineteenth-Century Europe (Urbana, Ill., 2008); Andrew Cunningham and Perry Williams, "De-centring the 'Big Picture': The Origins of Modern Science and the Modern Origins of Science," Brit. J. Hist. Sci. 26 (1993): 407-32.
} 
The history of singular science I shall present will of course be a selective one, reflecting the limits of my own knowledge. But I hope it will illuminate some aspects of the changing concepts of science and its history in the last two centuries. Positivism was not the only source of the aspiration to unify the sciences during this period, but a focus on the positivist movement will allow me to connect that aspiration to a specific historical consciousness that flourished in the same era. The positivist outlook included a place for historical studies, albeit a limited one. History was assigned a role that subordinated it to the sciences themselves, a role dictated by the vision of their eventual unification. As the influence of positivism has diminished in recent decades, history has assumed a more critical function. Historical and other studies have emphasized the differences between the disciplines, calling into question the purported singularity of the scientific enterprise and its tendency toward unity. At the same time, the rise to prominence of the biological and information sciences has undermined positivist assumptions about the hierarchy of the disciplines. This has coincided with important social and technological changes that have significantly altered the character of the scientific community and the perceived relationship between knowledge and technical practices. And the same period has also witnessed the diminished influence of European powers in global affairs, with consequent criticism of the idea that science has been uniquely a feature of Western civilization. All of these factors have undermined the traditional concept of singular science.

For historians of science, this situation raises an important set of questions. Should we cut ourselves loose from a concept of singular science that now looks decidedly threadbare? Can history of science simply rebrand itself "history of the sciences," acknowledging the plurality and diversity of its subject matter, and leave it at that? Or are there things we need to hang on to in the notion of singular science? Do we still require such an idea to secure the credentials of the field and provide it with a common agenda? My hope is that, by reviewing how we found ourselves at this point, we can reach toward some answers to these questions.

\section{NINETEENTH-CENTURY ORIGINS}

To begin, we need to go back to the early nineteenth century, since it was then that the modern conception of science as a singular and potentially unified entity was forged. This was a time of spectacular new discoveries and the creation of new disciplines. What was later called "classical physics" emerged at this time, centered on the phenomena of heat, light, and electricity, and on the concept of energy that linked them all. Chemistry underwent its own revolutionary developments, with crucial new findings about chemical composition. Biology arose from an intensified focus on the fundamental processes of life. The era also witnessed the growth of new institutions, including those specializing in the newly recognized disciplines. In response to these changes, a good deal of attention was devoted to trying to define science, to demarcate its boundaries and secure its standing in society. In the English-speaking world, the crucial metascientific works included John Herschel's Preliminary Discourse on the Study of Natural Philosophy (1830), Mary Somerville's On the Connexion of the Physical Sciences (1834), William Whewell's History of the Inductive Sciences (1837) and Philosophy of the Inductive Sciences (1840), and John Stuart Mill's System of Logic Ratiocinative and Inductive (1843). Looming over them was 
the massive oeuvre of Auguste Comte, the founder of positivism, whose Cours de philosophie positive was published between 1830 and 1842 .

What was new at this time was not the basic idea that all knowledge might be interconnected. That vision could be traced back to classical antiquity, and it had already inspired the encyclopedic projects of the eighteenth-century Enlightenment. What was new was the notion that science-meaning specifically the study of the natural world - could serve as the foundation for that unified knowledge. It was at this point that the English word science acquired a somewhat narrower meaning than it had had before, coming to designate the body of natural and physical sciences as opposed to knowledge more generally. The Oxford English Dictionary gives 1867 as the first date for this usage, but the passage adduced in illustration declares that the word already bears this meaning in common speech. Indeed, Whewell pointed toward this more restrictive meaning in his History of 1837, when he wrote that, by using the criterion of correct method, "some portions of knowledge may properly be selected from the general mass and termed SCIENCE."4

Although the meaning of the word science was apparently narrowed in this way, the influence of positivism and other European philosophical movements also led to a considerable expansion in its scope of application. Science came to designate a particular kind of knowledge, but it was also hailed as a model for all fields of inquiry and a focus for their potential unification. At the end of the nineteenth century, the historian J. T. Merz claimed that the vision of the unification of all human thought was the main achievement of the epoch, or "the higher work of our century." $\mathrm{As}$ champions of this vision, he mentioned both philosophers, such as Comte and Herbert Spencer, and scientists, such as Hermann von Helmholtz and Emil Du BoisReymond, who shared the positivist notion of a universal scientific method. The positivists saw science as the summation of all human endeavor, the final project in the historical progress of humanity. Far from being a narrowing of the conception of science, this amounted to a very grandiose vision of its historical importance. ${ }^{6}$

In Britain, it was Whewell who assumed the role of creating a study of science that would be external to scientific investigation as such but would secure its philosophical and historical credentials. ${ }^{7}$ Whewell not only coined the term scientist in 1833, but gave substantial theoretical support to the project of the British Association for the Advancement of Science (BAAS), to whom he suggested this neologism. As a result, he gained a lasting reputation-in certain quarters at least-as a founder of the history and philosophy of science. For Whewell, as for Comte and Mill, the crucial idea was that the different fields of scientific inquiry were potentially unified by a shared method, but that they had to be distinguished in terms of the progress

\footnotetext{
${ }^{4}$ William Whewell, Selected Writings on the History of Science, ed. Yehuda Elkana (Chicago, 1984), 5; emphasis in the original. I am aware, of course, that the same connotations do not surround the words normally translated as "science" in other European languages. The cognate terms generally cover a wider range of disciplines, and this suggests that the tendency to impute a singular identity to science may have been articulated more stridently in English-speaking countries than elsewhere.

5 John Theodore Merz, A History of European Scientific Thought in the Nineteenth Century, 4 vols. (London, 1904-12), 1:28-45, on 33.

${ }^{6}$ On positivism and the singularity of science in nineteenth-century Germany, see Peter Galison, "Introduction: The Contexts of Disunity," and Ian Hacking, "The Disunities of the Sciences," in Galison and Stump, Disunity of Science (cit. n. 2), 1-33 and 37-74.

${ }^{7}$ Richard Yeo, Defining Science: William Whewell, Natural Knowledge and Public Debate in Early Victorian Britain (Cambridge, 1993), 32-8, 145-75.
} 
they had made to date in implementing it. The notion of an ordering of the disciplines according to their different rates of progress was taken to be a distinct advance beyond earlier attempts - such as those of Herschel and Somerville - to relate the various sciences to one another. As G. H. Lewes later put it, Comte had shown that all sciences are "branches of one Science, to be investigated on one and the same Method."8 As Jack Morrell and Arnold Thackray have noted, the idea of singular science did important ideological work for the BAAS, helping to strengthen its relations with engineers, manufacturers, and professionals, and sharpening its appeal to the government from which it sought patronage. ${ }^{9}$

The fortified image of science was grounded in a sense of history. Whewell had an eye on the role played by contemporary political historians as he claimed the prerogative of legislator of science. Bound by a common method, the sciences were expected to look to history to measure their position along the path of progress. Some were recognizably more developed, and this was assumed to be because they dealt with simpler kinds of phenomena, though Whewell categorically denied that they could ever free themselves from metaphysical assumptions, as Comte had hoped. Nonetheless, Comte's classification of six fundamental disciplines-mathematics, astronomy, physics, chemistry, physiology, and sociology - was mirrored fairly closely in the six sections of the BAAS after 1833. And the order of the disciplines, as Lewes later explained, had a "necessary conformity to the actual order of the development of natural philosophy." He went on: "This is verified by all we know of the history of the sciences, particularly during the last two centuries." 10 Debate continued as to how rapidly and how exactly the moral sciences would catch up with planetary astronomy, which offered the prime example of the reduction of natural phenomena to mathematical laws. Whewell was skeptical that they would ever make the grade, and the BAAS accordingly confined social and political inquiries to the domain of "Statistics" in Section VI (later known as Section F). Mill agreed that it remained uncertain whether studies of mind or society were "capable of becoming subjects of science in the strict sense of the term." But he drew encouragement from the case of meteorology, which everyone seemed to expect would yield mathematical laws eventually, though it had failed to do so yet. As Mill explained: "The science of human nature . . . falls far short of the standard of exactness now realised in Astronomy; but there is no reason that it should not be as much a science as Tidology is, or as Astronomy was when its calculations had only mastered the main phenomena, and not the perturbations." ${ }^{11}$ Questions of scientific standing were thus brought before the tribunal of history, though the historical investigation that would resolve them was strictly constrained by a very specific theory of progressive development. In this manner, history became an auxiliary to the project of establishing singular science.

Conjoined in this way with a theory of scientific method, history was used to secure the authority of science in the nineteenth century. Positivism continued to be influential, and the later prominence of evolutionary thinking also strengthened the

${ }^{8}$ Lewes, Comte's Philosophy of the Sciences: Being an Exposition of the Principles of the "Cours de philosophie positive” of Auguste Comte (London, 1890), 10.

${ }^{9}$ Morrell and Thackray, Gentlemen of Science: Early Years of the British Association for the Advancement of Science (Oxford, 1981), 96, 224, 259-60.

${ }^{10}$ Lewes, Comte's Philosophy of the Sciences (cit. n. 8), 46.

${ }_{11}$ John Stuart Mill, A System of Logic, Ratiocinative and Inductive, people's ed. (London, 1896), $546,553-4$. 
historical mode of legitimation. The great Victorian sages of science, including T. H. Huxley, John Tyndall, and Karl Pearson, repeatedly invoked the historical vision of scientific progress in their writings. ${ }^{12}$ Though each of them recognized important differences among the individual disciplines, they deployed the notion of singular science strategically to uphold the credentials of science as a whole in relation to other cultural fields. In the later decades of the century, an evolutionary model of cultural progress strengthened the positivist expectation that science was destined to succeed theology and metaphysics. The theological outlook that had been so important earlier to the gentlemen of the BAAS was called into question. Instead of the framework of Christian belief being taken for granted, it became possible to conceive of religion as an observable feature of human cultures in general and a counterpart to science as a basic way of understanding the world. It has been noted that the term religion, applied in the eighteenth century to Judaism, Christianity, and Islam, began to be extended to cover the major Asiatic faiths at just the same time as science was acquiring its modern meaning. Thereafter, it became possible to think of religion and science as complementary and even opposed systems of thought. ${ }^{13}$ The end of the nineteenth century saw the emergence of some celebrated works arguing that science was inherently in conflict with religion. In their writings, J. W. Draper and A. D. White adopted the positivist assumption that science and religion were necessarily rivals, with the former destined to supersede the latter in the course of historical development.

Not all writers on science and religion in the period endorsed the "conflict thesis" concerning their relationship. The point is that it only became possible to conceive of the relationship - in these or other terms - when science had been defined as a singular entity, with which religion (similarly defined) could be compared. The consolidation of the notion of singular science also enhanced its claims for intellectual authority over material practice. In comments at the same meeting of the BAAS at which he proposed the word scientist, in Cambridge in 1833, Whewell explained how he saw the difference between scientific knowledge and that of the practical arts. The artisan's knowledge was inarticulate and restricted in its circulation, he claimed, whereas that of the scientist was explicit and public. The practitioners of the arts should therefore be guided by those who had a grasp of scientific theory. ${ }^{14}$ The differentiation of mental from manual labor, with its associated assumption that the mind should rule over the hand, was rooted in the thinking of the eighteenth-century Enlightenment, but it found a ready acceptance in the Victorian era. It was flattering both to those who saw themselves as theorists and to engineers and mechanics who aspired to the cultural validation that theoretical knowledge conferred. A few decades later, Tyndall defended a similar demarcation of science from mechanical skill in lectures at the Royal Institution in London. Somewhat more controversially, he also

12 Paul White, Thomas Huxley: Making the "Man of Science” (Cambridge, 2003), 67-99; Theodore M. Porter, Karl Pearson: The Scientific Life in a Statistical Age (Princeton, N.J., 2006).

${ }^{13}$ Peter Harrison, "Science' and 'Religion': Constructing the Boundaries," in Science and Religion: New Historical Perspectives, ed. Thomas Dixon, Geoffrey Cantor, and Stephen Pumfrey (Cambridge, 2010), 23-49.

14 Morrell and Thackray, Gentlemen of Science (cit. n. 9), 259-60; Yeo, Defining Science (cit. n. 7), 224-30. On changing notions of the relationship between scientific knowledge and material practice, see Lissa Roberts, Simon Schaffer, and Peter Dear, eds., The Mindful Hand: Inquiry and Invention from the Late Renaissance to Early Industrialization (Amsterdam, 2007). 
sought to redraw the lines dividing the domains of science and religion. ${ }^{15}$ Both of these strategic moves relied on the identification of singular science introduced by positivism.

Positivism also had important implications for the history of science. It promoted historical investigation while simultaneously tying it to the philosophical vision of the unity of the sciences. Comte called for the establishment of a chair in "general history of the sciences" at the Sorbonne as early as 1832, perceiving its importance in advancing his metascientific mission. History was to be enlisted in defense of the authority of singular science, which was defined by adherence to a common method. The historical record was to be interpreted in accordance with the positivist theory of progress, thereby contributing to the unification of the sciences. Although historical study was valuable in the metascientific realm, it had no necessary educational role for scientific practitioners themselves; in the mature sciences it should give way to a systematic presentation of the established facts. It would be quite incorrect, in Comte's view, to teach a science such as astronomy historically. ${ }^{16}$ In a sense then, the position of the history of science was both privileged and dependent. It was accorded primacy as the key to revealing the underlying method of the sciences and assigning each of them its correct place in the order of development. But history itself was not a science, and could not be one as long as it retained the narrative method and had not yet discovered its own laws. It was confined to a metascientific role, part of the positive philosophy that was itself to be transcended in the course of transition to a fully scientific era of human development.

\section{TWENTIETH-CENTURY VARIATIONS}

This paradoxical situation clearly irked George Sarton, the Belgian American who founded the journal Isis in 1913 and agitated consistently for the institutionalization of history of science in the first half of the twentieth century. Sarton's campaign was launched under the aegis of positivism, in which he had been interested from his early days as a student of philosophy. He professed admiration for the movement's founder, though he blithely acknowledged Comte's periodic bouts of mental instability. He even recorded having "communed" with the great man's spirit during a visit to his Paris home in the 1940s. ${ }^{17}$ Comte was worthy of veneration, Sarton maintained, though his historical scholarship never went beyond the superficial level. Sarton insisted on more rigorous scholarly standards in the history of science, in order to buttress its claim to independent academic standing. His perspective could still be described as positivist, however, with its emphasis on collecting and organizing factual information, compiling bibliographies, and establishing the institutional basis for the discipline. As Peter Dear has noted, Sarton also insisted on the singularity of the science whose history he was studying. While noting Comte's call for institutionalization of the discipline, he changed its designation from "history of the sciences"

\footnotetext{
15 Thomas F. Gieryn, “John Tyndall's Double Boundary-Work: Science, Religion, and Mechanics in Victorian England," in Gieryn, Cultural Boundaries of Science (cit. n. 2), 37-64.

${ }^{16}$ Gertrud Lenzer, ed., Auguste Comte and Positivism: The Essential Writings (New York, 1975), 91-3.

${ }^{17}$ George Sarton, "Auguste Comte, Historian of Science: With a Short Digression on Clotilde de Vaux and Harriet Taylor," Osiris 10 (1952): 328-57.
} 
to "the history of science."18 The reformulation was crucial. As far as Sarton was concerned, the unity of science would emerge from properly conducted historical scrutiny. To encourage this, it was necessary to step back from the small-scale details of scholarship and take the long view. The minutiae of developments in the different scientific disciplines were less relevant to Sarton than the consolidated knowledge formalized in textbooks. Stories of individual accomplishment should ideally be synthesized into general accounts of eras and cultures. Then, the overall pattern of progress would be discerned and the unity of scientific knowledge correctly grasped. Sarton's Introduction to the History of Science was projected as a massive and comprehensive work to convey this unified vision. It was never more than partially completed, two volumes being published in 1927 and one more in 1948.

Sarton's vision of the discipline combined his positivist outlook with a deeply held commitment to pacifism and international solidarity. He believed that the codification and unification of all human knowledge would form the basis of global harmony and point the path toward the ending of military conflict. Launching his journal Isis on the eve of World War I, Sarton insisted that the positivist ideal of the unity of science was a buttress against national and ethnic rivalries, a prop for international cooperation, and a spur toward human unity. The grim alternative was intellectual and social fragmentation. As he later put it: "The fact that the building up of science has been done in the past and is done today by men of various races and many nationalities, inspired by different faiths, speaking different languages, proves that these men have the same needs and aspirations, reason in the same way, and, as far as they collaborate in the essential task of mankind, are united."19 In Sarton's vision, then, the history of science was the heritage of the human species as a whole, a testimony to its common investment in the essential task of mankind. Sarton thus gave singular science its most profound significance, hailing its development as the central theme of human history and the brightest hope for the future.

The vision of singular science as a collective enterprise of humanity as a whole was shared by other inheritors of the positivist outlook in the early twentieth century. As Lewis Pyenson and Christophe Verbruggen have shown, Sarton drew upon the work of the Belgian bibliographers Paul Otlet and Henri-Marie Lafontaine, whose attempts to categorize and index all knowledge reflected their internationalist vision. ${ }^{20}$ Sarton's activities in turn inspired those of the Italian scholar Aldo Mieli, founder of the Archivio di storia della scienza in 1919 (renamed Archeion in 1927) and of the International Academy of the History of Science in 1929. ${ }^{21}$ Similar political ideals informed the work of the Unity of Science movement, associated with the logical positivists of the Vienna Circle. Members of this group, including Otto Neurath, Philipp Frank, Charles Morris, and Rudolf Carnap, emphasized the methodological features common to all of the sciences. Their approach was philosophical rather than historical, but it issued in an encyclopedic project similar in scope to Sarton's and more

\footnotetext{
${ }^{18}$ Dear, "The History of Science and the History of the Sciences: George Sarton, Isis, and the Two Cultures," Isis 100 (2009): 89-93.

${ }^{19}$ George Sarton, "Four Guiding Ideas," in Sarton on the History of Science, ed. Dorothy Stimson (Cambridge, Mass., 1962), 15-22, on 15. This essay was originally published in 1947.

${ }^{20}$ Pyenson and Verbruggen, "Ego and the International: The Modernist Circle of George Sarton," Isis 100 (2009): 60-78.

${ }^{21}$ Robert Fox, "Fashioning the Discipline: History of Science in the European Intellectual Tradition," Minerva 44 (2006): 410-32.
} 
extensively realized: the International Encyclopedia of Unified Science, of which twenty monographs were published by the University of Chicago Press between the mid-1930s and the early 1960s. For Neurath, the unification of scientific knowledge was a distant prospect rather than an immediate goal; the encyclopedia was intended to facilitate the communication among scientists that could gradually bring it about. His campaign for this kind of unification was linked to his belief in socialist economic planning, which he attempted to put into practice in the short-lived Bavarian revolution after World War I, in leftist administrations in Vienna, and in work with the Bauhaus movement in the Weimar Republic. ${ }^{22}$ Frank, an Austrian physicist and philosopher of liberal outlook, and Morris, an American pragmatist philosopher, shared to some degree Neurath's social vision for the Unity of Science project.

The social dimension of the movement was largely lost sight of after its leading members relocated to the United States in the 1930s, especially in the face of the concerted anticommunist campaign in the years after World War II. During the Cold War, American suspicion of internationalist and socialist political programs led to the rise of a purely technical version of logical positivism, associated with Carnap, Hans Reichenbach, and Herbert Feigl. As George A. Reisch has recently documented, Neurath's death in 1945 left the movement without the most articulate spokesman for its political vision. ${ }^{23}$ Morris faced pressure from anticommunist agitators in Chicago, while Frank and Carnap were subjected to FBI investigation as suspicious foreigners. At this juncture, logical positivism was refocused on technical issues of epistemology, abandoning the popular and collectivist social aims originally invested in the Unity of Science movement.

The idea of singular science nonetheless lived on, accorded a common respectthough understood differently_ by each side in the fierce ideological conflicts of the middle decades of the twentieth century. Despite deep divisions between Marxists and anti-Marxists in this period, both sides sought to borrow the cultural capital of science. In some respects, twentieth-century Marxism nurtured a continuation of the positivist tradition, though positivism was also fiercely criticized in some communist countries for its opposition to materialist metaphysics. Many Marxists embraced the notion of singular science, often claiming that dialectical materialism itself had scientific status and had revealed the long-sought laws of historical development. ${ }^{24}$ The internationalist outlook associated with this was upheld by such leftist scholars as Joseph Needham and Benjamin Farrington, both of whom were involved with the UNESCO (United Nations Educational, Scientific, and Cultural Organization) Committee for History and Social Relations of Science in the 1940s.

On the other hand, the anti-Marxists who played an important role in institutionalizing the history of science in the West conceded nothing in their admiration of science, though they often understood it in a pointedly antipositivist manner. Thus, the Russian émigré Alexandre Koyré set out his idealist model, in which scientific knowledge was said to rely on metaphysical foundations adopted prior to sensory

\footnotetext{
${ }^{22}$ Richard Creath, "The Unity of Science: Carnap, Neurath, and Beyond," and Jordi Cat, Nancy Cartwright, and Hasok Chang, "Otto Neurath: Politics and the Unity of Science," in Galison and Stump, Disunity of Science (cit. n. 2), 158-69, 347-69.

${ }^{23}$ Reisch, How the Cold War Transformed Philosophy of Science: To the Icv Slopes of Logic (Cambridge, 2005), esp. 1-26, 259-76.

24 Terrell Carver, "Marx and Marxism," in The Cambridge History of Science, vol. 7: The Modern Social Sciences, ed. Theodore M. Porter and Dorothy Ross (Cambridge, 2003), 183-201.
} 
experience. Koyré was strongly antipathetic to Marxism or anything tainted by association with it; his views had a deep influence on conceptions of the "Scientific Revolution" of the sixteenth and seventeenth centuries. For Koyré, the intellectual transformation of that era was identified with the rise of a new theory of motion and the "geometrization" of space, especially in the works of Galileo and Descartes. ${ }^{25}$ Koyré's antipositivist and antiempiricist conception of science was influential with a whole generation of American and British historians, including Herbert Butterfield, A. Rupert Hall, and Richard S. Westfall. ${ }^{26}$ On a more popular level, the books of the Hungarian writer Arthur Koestler also advocated an idealist view of science, in which individual geniuses such as Johannes Kepler assumed the role of intellectual revolutionaries. A recent biography of Koestler has shown how he was drawn to metaphysical and psychological studies of science after gaining fame as an anticommunist novelist and polemicist in the postwar period. ${ }^{27}$

Thus, singular science enjoyed veneration on both sides of the ideological gulf of these years. Marxist historians, from the Soviet physicist Boris Hessen in the 1930s to the Irish crystallographer J. D. Bernal in the 1950 s, tended to accept a rather similar characterization of the intellectual contents of science as their anti-Marxist opponents. They set out to uncover the material and economic needs that had given rise to the intellectual structure in question. ${ }^{28} \mathrm{~A}$ recent commentator has written of Bernal, "He was quite as 'idealist' a historian of scientific ideas as anyone can imagine in the 'bourgeois camp." 29 Marxists shared with their ideological enemies a tendency to view science as a single thing, primarily identified with a set of metaphysical assumptions that could change dramatically in quite a short period. Hence the common interest in the Scientific Revolution of the early modern era. The gaps appeared in other areas of history, such as the Enlightenment, which was not properly brought into focus by either camp. Idealists tended to see the eighteenth-century movement as a mere aftershock of the intellectual revolution of the previous century, while Marxists viewed it as a bourgeois diversion prior to the more important Industrial Revolution. ${ }^{30}$

Nobody better demonstrates the ambiguities of Marxist historiography in the twen-

${ }^{25}$ Roy Porter, "The Scientific Revolution: A Spoke in the Wheel," in Revolution in History, ed. Porter and Mikuláš Teich (Cambridge, 1986), 290-316; David C. Lindberg, "Conceptions of the Scientific Revolution from Bacon to Butterfield: A Preliminary Sketch," in Reappraisals of the Scientific Revolution, ed. Lindberg and Robert S. Westman (Cambridge, 1990), 1-26.

${ }^{26}$ David A. Hollinger, "Science as a Weapon in Kulturkämpfe in the United States during and after World War II," Isis 86 (1995): 440-54; Anna K. Mayer, "Setting Up a Discipline: Conflicting Agendas of the Cambridge History of Science Committee, 1936-1950," Stud. Hist. Phil. Sci. 31 (2000): 665-89.

${ }^{27}$ Michael Scammell, Koestler: The Literary and Political Odyssey of a Twentieth-Century Skeptic (New York, 2009).

${ }_{28}$ On Hessen, see Loren R. Graham, "The Socio-political Roots of Boris Hessen: Soviet Marxism and the History of Science," Soc. Stud. Sci. 15 (1985): 705-22; Gary Werskey, The Visible College: A Collective Biography of British Scientists and Socialists of the 1930s, 2nd ed. (London, 1988), 13849; Anna K. Mayer, "Setting Up a Discipline II: British History of Science and the 'End of Ideology,' 1931-1948," Stud. Hist. Phil. Sci. 35 (2004): 41-72. On Bernal, see Andrew Brown, J. D. Bernal: The Sage of Science (Oxford, 2005).

${ }^{29}$ H. Floris Cohen, The Scientific Revolution: A Historiographical Inquiry (Chicago, 1994), 220.

${ }^{30}$ For more on the neglect of Enlightenment science, see William Clark, Jan Golinski, and Simon Schaffer, "Introduction," in The Sciences in Enlightened Europe, ed. Clark, Golinski, and Schaffer (Chicago, 1999), 3-31. 
tieth century than the English Sinologist Joseph Needham. Needham's monumental studies of the history of Chinese science opened up the issue of the comparative study of non-European cultures, with important implications for the notion of singular science. Needham had a famously heterodox intellectual formation, in which Marxism, Christianity, and Taoism jostled in sometimes uneasy proximity, and his massive scholarly labors gave him an unrivaled knowledge of Asian and European cultures. With his training in biochemistry and developmental biology, he was uncomfortable with the positivist hierarchy of the sciences. He disputed the right of physics to be considered the model for all science, though he sometimes also paid homage to the idea that science was a singular entity. He said the initial spur to his research on China was the question of why modern science had arisen only in Europe- a formulation that took for granted that science was defined by the European experience. But, as Needham's research accumulated, it succeeded in showing the magnitude and range of the Chinese accomplishment and implicitly made the case for the diversity of sciences in different cultures. ${ }^{31}$ So, although the famous "Needham question" was premised on an assumption of the singularity of science, in the end his work undermined the whole idea that science was a uniquely European enterprise. As H. Floris Cohen has shown, Needham gave no definitive or unambiguous answer to his own question. While he cited Koyré's description of the Scientific Revolution as a transformation in metaphysics, he denied its completeness because it ignored the biological sciences. ${ }^{32}$ Needham also included technology and medicine within his capacious vision, unlike Koyré, who firmly segregated such applied fields from science's intellectual core.

In these ways, Needham pointed forward to the new world in the last few decades of the twentieth century, in which notions of singular science had to be reconsidered. Assumptions of the uniqueness of European modes of understanding were increasingly called into question in an era of increased global communications. Progressive politics in the West, which used to be identified with the unification of the sciences and the singularity of the European achievement, now came to embrace multiculturalism, which implied that the sciences might take forms other than just the canonical one. Needham was a critical figure in this transformation. Sometimes he emphasized the singularity of science as the common enterprise of humankind as a whole, in the internationalist manner of Sarton, Neurath, and Bernal. At other times, he acknowledged its diversity in relation to cultural differences and historical change. In this way, he foreshadowed the trouble that lay ahead for the idea of singular science.

Needham's farsightedness in this connection is illuminated by a comparison with his Cambridge contemporary C. P. Snow. Snow's much-discussed lecture of 1959 , "The Two Cultures and the Scientific Revolution," confidently reiterated the notion

\footnotetext{
${ }^{31}$ Gregory Blue, "Joseph Needham," in Cambridge Scientific Minds, ed. Peter Harman and Simon Mitton (Cambridge, 2002), 299-312; Simon Winchester, The Man Who Loved China: The Fantastic Story of the Eccentric Scientist Who Unlocked the Mysteries of the Middle Kingdom (New York, 2008); Needham, The Grand Titration: Science and Society in East and West (London, 1969); Needham, "The Making of an Honorary Taoist," in A Selection from the Writings of Joseph Needham, ed. Mansel Davies (Jefferson, N.C., 1990), 29-54; Needham, Science and Civilization in China, ed. Christopher Cullen, 24 vols. (Cambridge, 1954-).

${ }^{32}$ Cohen, Scientific Revolution (cit. n. 29), 418-82, esp. 445.
} 
of the singularity of science. ${ }^{33}$ By "the scientific revolution," Snow meant not the early modern shift in metaphysical outlook described by Koyré, but the ongoing technological transformation of modern society since industrialization. The key to this process, in Snow's view, was the knowledge base of Western science. He proclaimed that European scientific education was the sine qua non of material progress. Countries elsewhere in the world had simply to educate scientists in the approved way and industrial development would follow. Snow's outlook was thoroughly imbued with the assumption of the uniqueness of European science and the particular version of internationalism that derived from it. And, of course, he also trumpeted the singularity of scientific culture when contrasting it with that of literary intellectuals. The scientific and the literary spheres constituted the "two cultures" for which his lecture became famous. Comparing science with a degenerate literary modernism, he declared that the former was superior both as an intellectual outlook and as a repository of moral values. He subsequently resisted proposals that the two cultures should be increased to three or more to recognize the social sciences or other academic fields. Singular science remained crucial to Snow's whole perspective. And because his lecture was so influential—not least in inspiring the establishment of programs in history of science and allied subjects to "bridge" the two cultures-he breathed new life into the notion.

Just three years later, however, Thomas S. Kuhn's Structure of Scientific Revolutions provided the occasion for more intensive scrutiny of singular science. ${ }^{34}$ This is not to say that Kuhn was setting out to completely subvert established ideas. In fact, it has been plausibly argued that his aims were not really radical at all, and his influence was out of all proportion to his intentions. In many respects, he stuck closely to the classical notion of singular science. His idea that certain "paradigms" guide the development of the "mature" scientific disciplines suggested a uniform standard of method. And he closely followed the positivist hierarchy of the disciplines in marking when different fields had achieved paradigmatic form: the mathematical sciences in antiquity, experimental physics in the seventeenth and eighteenth centuries, chemistry somewhat later, and the biological sciences only in the nineteenth century and since. When Kuhn declared that the social sciences had yet to create their paradigms, he was echoing Comte's sentiments of more than a century before. Furthermore, mature, paradigmatic, or "normal" science was characterized by Kuhn as a selfcontained world, largely segregated from those large-scale social forces he classified as "external." ${ }^{35}$ As such commentators as Steve Fuller have pointed out, this clearly reflected the assumptions of the Cold War scientific intelligentsia from which Kuhn emerged. ${ }^{36}$ It was taken for granted in those circles that scientific progress would take the form of increasing specialization and professionalization of the various fields of research. Scientists were expected to focus on ever-narrower topics of study as they isolated themselves institutionally, organizing their own social arrangements

${ }^{33}$ Snow, The Two Cultures (Cambridge, 1993).

${ }^{34}$ Kuhn, The Structure of Scientific Revolutions, 2nd ed. (Chicago, 1970).

35 Ibid., 69. See also Steven Shapin, "Discipline and Bounding: The History and Sociology of Science as Seen through the Externalism-Internalism Debate," Hist. Sci. 30 (1992): 333-69.

${ }^{36}$ Fuller, Thomas Kuhn: A Philosophical History for Our Times (Chicago, 2000), 1-37. See also Reisch, How the Cold War (cit. n. 23), 229-33; Philip Mirowski, "What's Kuhn Got to Do with It?" in The Effortless Economy of Science? (Durham, N.C., 2004), 85-96. 
independently of forces in the wider society. Again reflecting the assumptions of his milieu, Kuhn remarked that this form of social organization had originated in early modern Europe and was to be found exclusively in the cultures that descended directly from it. ${ }^{37}$

On the other hand, Kuhn's book was received in an intellectual climate that was growing increasingly skeptical about the idea of singular science. ${ }^{38}$ Many contemporaries read his work as opening the door to a more discriminating and rigorously historical account. Kuhn was more a symbol of these changes than a leader of them; he subsequently disavowed what he took to be the wildest misinterpretations of his work. But that does not mean that those who perceived radical implications in his writings were altogether mistaken. ${ }^{39}$ In certain respects, Kuhn's model did undermine the program of singular science, despite the fact that the book appeared as a volume in the International Encyclopedia of Unified Science, founded by Neurath and his colleagues from the Vienna Circle. Kuhn noted that scientific methods and practices were not universal, but localized within quite tightly bounded communities of practitioners. He acknowledged that phenomena could not be observed raw, but were always interpreted through a framework of preconceptions and according to assumptions bound up with the use of certain instruments. And he recognized that, while paradigms guided scientific research, they did not determine what sense could be made of new experiences. Concepts did not come prepackaged with all of their possible applications; they were fitted to the findings of inquiry by a process of interpretive fudging and creative extrapolation. If one took seriously these aspects of Kuhn's perspective, then science appeared as a methodologically looser and much more fragmented activity than the positivist tradition had allowed.

One group of his interpreters who developed Kuhn's insights in this direction were the members of the Edinburgh school, who advanced the so-called Strong Programme in science studies in the 1970s and early 1980s. The philosopher David Bloor and the sociologist Barry Barnes seized particularly on Kuhn's debts to the philosophy of Ludwig Wittgenstein. ${ }^{40}$ Kuhn's vision of normal science as the creative and undetermined extension of existing ideas echoed Wittgenstein's insistence that rational thought was not governed by logical rules and that language was always changing in response to practical needs. This suggested that the meanings of scientific ideas were related to the local circumstances and immediate needs of investigators; they were not determined by logical deduction from some more general theory. To the Edinburgh school, the fundamental implication of this was clear, though Kuhn himself had not perceived it. Science was a social enterprise at its very core, since the concepts and methods that constituted paradigms were the attributes of small

${ }^{37}$ Kuhn, Structure of Scientific Revolutions (cit. n. 34), 168.

${ }^{38}$ For background, see Michael Aaron Dennis, "Historiography of Science: An American Perspective," in Companion to Science in the Twentieth Century, ed. John Krige and Dominique Pestre (London, 2003), 1-26; Hollinger, "Science as a Weapon" (cit. n. 26).

${ }^{39}$ For a more developed argument on this point, see Jan Golinski, "Thomas Kuhn and Interdisciplinary Conversation: Why Historians and Philosophers of Science Stopped Talking to One Another," in Integrating History and Philosophy of Science: Problems and Prospects, ed. Seymour Mauskopf and Tad M. Schmaltz (Dordrecht, 2012). A contrasting account of recent trends in science studies, which roots them in a series of "misunderstandings" of the works of postpositivist philosophers, is given by John H. Zammito, A Nice Derangement of Epistemes: Post-positivism in the Study of Science from Quine to Latour (Chicago, 2004).

${ }^{40}$ Barnes, T. S. Kuhn and Social Science (London, 1982); Bloor, Wittgenstein: A Social Theory of Knowledge (London, 1983); Bloor, Knowledge and Social Imagery, 2nd ed. (Chicago, 1991). 
groups united by their focus on a common task. Social relations within such groups had an immediate bearing on how science was done; they were not at all external to its practice.

The most prominent application of this claim was in the studies of scientific controversies that flourished among historians and sociologists of science in the 1980s. The sociologists Harry Collins and Trevor Pinch led the way, documenting the disputes over physicists' attempts to detect gravity waves or solar neutrinos. ${ }^{41}$ Historical studies followed in their footsteps, by Steven Shapin, Simon Schaffer, Martin Rudwick, James Secord, and others. They scrutinized the controversies surrounding Robert Boyle's experiments with the air pump, Isaac Newton's work on light and colors, and Victorian geologists' mapping of the Earth's strata. ${ }^{42}$ When such debates were studied with due attention to both sides, they seemed to be not just about facts, but about methods, instruments, competences, and indeed the whole direction science should take. What Kuhn had called "incommensurable paradigms" seemed to be squaring off against each other. In Kuhn's own phrase (echoing Wittgenstein), "incompatible modes of community life" were at stake. ${ }^{43}$ The methods and practices of the sciences were found to differ, not just in different civilizations and nations, but even at the level of individual researchers. With the exposure of such apparently unbridgeable chasms between practitioners in the same field, a sharp blow was dealt to the notion of singular science.

\section{CONTEMPORARY PROSPECTS}

The exposure of deeply rooted controversies at the leading edges of scientific research is but one of the ways in which the idea of singular science has been eclipsed in recent years. The themes of diversity, disunity, and localism have come to overshadow those of consistency, unification, and universalism in analyses of scientific practice. There are many factors that have shaped the current situation, and it is clear that only a small part of the responsibility can be laid at the door of Thomas Kuhn. In the last few decades, the field of science studies has come to embrace political, economic, and literary disciplines, as well as the traditional triad of history, philosophy, and sociology. These academic interests have intersected in complex ways with broader cultural and intellectual changes, often summarized under the label postmodernism, and with remarkable developments in the sciences themselves. As individuals of all nations have become scientists, questions of cultural diversity have been raised much more directly than C. P. Snow could ever have imagined. The entry of more women into professional positions has both inspired and been encouraged by

\footnotetext{
${ }^{41}$ Collins, Changing Order: Replication and Induction in Scientific Practice (Beverly Hills, Calif., 1985); Pinch, Confronting Nature: The Sociology of Solar Neutrino Detection (Dordrecht, 1986).

${ }^{42}$ Shapin and Schaffer, Leviathan and the Air-Pump: Hobbes, Boyle, and the Experimental Life (Princeton, N.J., 1985); Schaffer, "Glass Works: Newton's Prisms and the Uses of Experiment," in The Uses of Experiment: Studies in the Natural Sciences, ed. David Gooding, Pinch, and Schaffer (Cambridge, 1989), 67-104; Rudwick, The Great Devonian Controversv: The Shaping of Scientific Knowledge among Gentlemanlv Specialists (Chicago, 1985); Secord, Controversy in Victorian Geology: The Cambrian-Silurian Dispute (Princeton, N.J., 1986). Also important in directing historians' attention to the value of the Edinburgh perspective was Shapin, "History of Science and Its Sociological Reconstructions," Hist. Sci. 20 (1982): 157-211.

${ }^{43}$ Kuhn, Structure of Scientific Revolutions (cit. n. 34), 94.
} 
increased academic attention to the role of gender in science. These changes have enhanced the appeal of a model of science that emphasizes pluralism rather than unification, and that recognizes how knowledge remains tied to the attributes of local cultures rather than entirely escaping from them. In addition, scientific knowledge has been implicated as both cause and effect in the staggering technological advances of recent decades. The ubiquity of information technology in all kinds of scientific research has made it impossible to maintain the fiction that technological change is always dependent on prior advances in "pure" science. The rise of the biological sciences has been especially notable in this period, undermining the positivist claim that physics is the preeminent discipline. Additional sciences have emerged with bewildering rapidity, and interdisciplinary fields have proliferated as the foci of research and pedagogy. All of this has tended to confirm the impression that the traditional notion of a singular and prospectively unified science is obsolete-that the diverse fields of contemporary inquiry and innovation cannot all be subordinated to a single method or ideal.

In this situation, historical studies have turned for inspiration to philosophical traditions other than positivism, in which the singularity of science has not been so readily accepted. In a recent account of these traditions, Hans-Jörg Rheinberger has argued that Kuhn did no more than synthesize the conclusions of "a protracted effort that took various forms over a good half-century, despite the contemporary philosophical dominance of logical positivism." 44 Rheinberger locates the roots of scientific pluralism in the turn toward history by certain philosophers of science in the early twentieth century. He points in particular to the importance of the 1920s, when ideas about the plurality of scientific cultures were provoked partly by the revolutionary developments in physics and partly by reflections on the biological sciences. The former were of interest to the French philosopher Gaston Bachelard, who drew the conclusion that scientific ideas were tied to very localized arrangements of experimental apparatus and the phenomena they exhibited. Working in the biological sciences at the same time, the Polish immunologist Ludwik Fleck drew similar conclusions about the local specificity of scientific cultures. Fleck wrote of the styles of thinking characteristic of particular laboratories and of the material practices that lay behind them. The writings of these two authors, along with the more general philosophical perspectives of Edmund Husserl, Martin Heidegger, and Ernst Cassirer, are seen by Rheinberger as having laid the foundations for the more widespread emergence of pluralistic notions of science in the years after World War II.

Rheinberger's narrative can be read as a counterpart to my own. While I have traced the long legacy of nineteenth-century positivism, he has shown that it was nurturing the roots of postpositivism even during its heyday. At the least, this serves as a salutary corrective to the temptation to see pluralistic ideas about science as entirely due to very recent cultural trends. Taking that line, some commentators have sought to pin the blame on the liberalism of the 1960s, on the feminism and postcolonialism that emerged from that decade, or on the postmodernism that came to the fore in the 1980s. These were the targets in the so-called science wars of the 1990s, when what was thought to be an attack on science drew forth a vituperative response from

${ }^{44}$ Rheinberger, On Historicizing Epistemology: An Essay (Stanford, Calif., 2010), 79-80. 
its self-appointed defenders. ${ }^{45}$ The clamor of that battle should not obscure the fact that criticisms of the positivist vision of science had been brewing for several decades already. And a central feature of these criticisms was the theme that science was not a singular thing. To those who recognized this, the science wars seemed like a noisy distraction, a hubbub of mutual incomprehension. If science is not a single entity, then it is not really possible either to attack or to defend it as such. Critics of the notion of the singularity of science were not, of course, attacking the sciences, or even any part of them. Nor were they likely to be persuaded by reiterations of the traditional positivist line by those who claimed to be defending science itself.

If the polemics of the 1990s confirmed that the idea of singular science had taken a beating by the end of the twentieth century, they also showed that it was not entirely extinct. Indeed, some of those who sprang to the defense of science enthusiastically reasserted the possibility of the unification of scientific knowledge. A few physicists prophesied the imminent reduction of natural phenomena to a single allencompassing law, or the unification of physical forces through new discoveries of subatomic particles. Some biologists foresaw the expansion of Darwinian natural selection beyond plants and animals to cover the evolution of the inorganic world and human culture as well. Visions of the singularity of science, it seemed, could themselves take multiple forms. On the other hand, even while the onslaughts of the critics were being vehemently repulsed, the journalist John Horgan found several prominent scientists who acknowledged that singular science as it had traditionally been understood was coming to an end. ${ }^{46}$ In the course of a series of interviews with leading practitioners, he uncovered what he called an "ironic" attitude of contemporary scientists to their past. Many of them were highly conscious of the complexities and discontinuities in the historical record, hesitant to predict the future, reluctant to prophesy that the truth would finally be found, and aware that-in the long termcurrent ideas would pass away. As Horgan pointed out, this kind of ironic sophistication about the history of science is also a widespread characteristic of our age.

This complex situation frames current debates about the central issue I have been discussing: the relationship between the belief that science is a singular entity and the consciousness of its history. In the positivist tradition, the history of science was read as a narrative of progress, of the accumulation of knowledge and the gradual reduction of phenomena to regular laws. This account provided a guarantee that scientific knowledge would in time be unified, as the different disciplines in turn attained the form of a true science. The scientists Horgan interviewed seem to have realized that that guarantee has now been withdrawn. Singular science, whose unity was forecast on the basis of a specific interpretation of the past, has lost the warrant of history. In this sense, if in no other, the end of science is upon us.

Professional historians, at least, seem unworried by this. Indeed, they have experienced the release from positivist expectations as something of a liberation. Few historical narratives now trumpet unidirectional progress and the march toward the unification of knowledge. On the contrary, most of them stress fragmentation and

${ }^{45}$ For illuminating commentary on the science wars, see Gieryn, Cultural Boundaries of Science (cit. n. 2), 336-62; Arkady Plotnitsky, The Knowable and the Unknowable: Modern Science, Nonclassical Thought, and the "Two Cultures" (Ann Arbor, Mich., 2002), 157-99; John Guillory, "The Sokal Affair and the History of Criticism," Crit. Inq. 28 (2002): 470-508.

${ }^{46}$ Horgan, The End of Science: Facing the Limits of Knowledge in the Twilight of the Scientific Age (New York, 1996). 
localization. In this manner, research on the history of the sciences has largely freed itself from the notion of singular science, which was its primary source of legitimacy when positivism held sway. In addition, recognizing the plurality and disunity of the sciences makes it easier to claim a place for history among them. No longer striving to model itself after the physical sciences, history can escape from the subordinate position to which positivism confined it. One can even argue, as Roger Smith has recently, that all humanistic study is historical to one degree or another, and hence that history has a fundamental role in all of the "human sciences." 47

On the other hand, the retreat of the idea of singular science leaves unfinished business in its wake. The traditional notion presented answers to a series of questions - answers that we no longer find adequate but have yet to replace fully. Science was supposed to present a single path to the truth, a truth that would necessarily prevail everywhere and would yield intellectual command over material practice. Science was supposed to be inherently egalitarian and public, yet unencumbered by economic interests or political forces. If we no longer find this vision convincing, we have to derive new ways to respond to the questions it was originally intended to answer. We need new explanations for the extraordinary geographical range over which scientific knowledge has proven itself, its intimate relationship with technology, and its institutionalization in diverse cultures. These questions of the character and context of scientific knowledge remain fundamental, even if we jettison the truisms by which they were traditionally answered. They constitute key issues surrounding the historical role of the sciences in the modern era. And it is the heritage of engagement with these issues that distinguishes what has been called the history of science from other fields of historical study.

A lot has been done along these lines, though much still remains to be done. As singular science was deconstructed into a patchwork of diverse and localized forms of knowledge, the pressing issue arose of explaining how that knowledge escaped the local circumstances of its origin and was given more general acceptance. Answers have been sought in the various social mechanisms through which artifacts, people, and texts are mobilized. Practices of translation, replication, and metrology have taken the place of the universality that used to be assumed as an attribute of singular science. When science was thought of as the same everywhere, its uniformity mapped directly onto that of nature itself. In the new view, science achieves its singularity - to the extent it does - as the result of practices that are socially and historically located. These practices have been brought under scrutiny by historians, sociologists, philosophers, and others, whose task has been to show how scientific knowledge is made to seem universal and consistent - in other words, to fill the gap left by the disappearance of the idea of singular science. Through their efforts, a fair amount has been revealed about the mechanisms by which scientific knowledge has circulated through modern society and across geographical space. ${ }^{48} \mathrm{~A}$ picture is emerging that stresses the role of networks and circulation in allowing knowledge to 2007).

${ }^{47}$ Smith, Being Human: Historical Knowledge and the Creation of Human Nature (Manchester, 2007).

${ }^{48}$ Surveys of this work include Steven Shapin, "Here and Everywhere: Sociology of Scientific Knowledge," Annu. Rev. Sociol. 21 (1995): 289-321; Jan Golinski, Making Natural Knowledge: Constructivism and the Historv of Science (Chicago, 2005); David N. Livingstone. Putting Science in Its Place: Geographies of Scientific Knowledge (Chicago, 2003); James A. Secord, "Halifax Keynote Address: Knowledge in Transit," Isis 95 (2004): 654-72. 
transcend the cultures, languages, and communities within which it originates. We are beginning, in other words, to formulate an alternative model. But, as long as this remains a collective work in progress, we can still expect to have it measured against the all-too-easy answers provided by the notion of singular science. The legacy of that notion still bears heavily upon us, and is not easily to be shrugged off. We have not yet arrived at the point when we can forget science. 